\title{
ARQUITETURA E ENERGIA SOLAR: HÁ ALGO DE NOVO?
}

\begin{abstract}
DOMINIQUE FRETIN*
*Possui graduação em Arquitetura e Urbanismo pela Universidade de São Paulo (1974), mestrado(2002) e doutorado (2009) em Arquitetura e Urbanismo, ambos pela Universidade Presbiteriana Mackenzie. Atualmente é pesquisador da Universidade Presbiteriana Mackenzie e professor assistente na faculdade de Arquitetura e Urbanismo desta mesma Universidade. Tem experiência na área de Arquitetura e Urbanismo, com ênfase em Tecnologia de Arquitetura e Urbanismo, atuando e lecionando principalmente nos seguintes temas: arquitetura, energia solar, sustentabilidade, projeto de arquitetura, qualidade de vida, eficiência energética e conforto ambiental (Térmica, acústica, insolação, ventilação, iluminação natural).

Endereço para acessar CV Lattes: http://lattes.cnpq.br/6612511393884906

e-mail: dominixme@gmail.com
\end{abstract}

\section{RESUMO}

Não há dúvidas quanto à evolução do aproveitamento da energia solar e ao progresso acelerado das técnicas capazes de explorar esta forma de energia. A novidade está na transformação da radiação solar em eletricidade da qual a humanidade não prescinde mais, mas outras formas de se utilizar esta energia, luz e calor, e notadamente na arquitetura e nas construções são tão antigas quanto a história registrada. Mesmo assim, a assimilação de tais possibilidades na arte de construir ainda parece caminhar lentamente. A pergunta que orienta este artigo busca indagar se a adoção desta forma de energia trará modificações na forma dos edifícios e no desenho urbano, vindo a transformar a paisagem das cidades? Um breve levantamento do "estado da arte" tenta elucidar estas questões.

Palavras-chave: Energia solar, arquitetura, cidades, eficiência energética, edifícios e cidades sustentáveis.

\section{ARCHITECTURE AND SOLAR ENERGY: IS THERE ANYTHING NEW?}

\begin{abstract}
There is no doubt as to the evolution of the solar energy yield and the accelerated progress of techniques able to exploit this type of energy. The novelty lies in the transformation of solar radiation into electricity, which mankind cannot disregard anymore, but other ways to use such energy, light and heat, which are as old as the recorded
\end{abstract}


in the architecture history and constructions. Even so, the assimilation of such possibilities in the constructing art still looks going on slowly. The question that guides this article seeks to ask if the adoption of this form of energy will bring changes in the form of buildings and urban design, transforming the landscape of the cities. A brief survey of the "state of the art" attempts to clarify these issues.

Keywords: Solar energy, architecture, cities, energy efficiency, sustainable buildings and cities.

Em épocas de crise, carência de energia ou preocupações com o abastecimento futuro é natural que os espíritos se voltem para a busca de fontes alternativas viáveis e urgentes. A energia solar, a principio inesgotável, pelo menos na escala de tempo humana, fonte primária e base de quase todas as fontes usadas hoje (com exceção da nuclear e da geotérmica) retorna sempre à pauta. O processo não é novo e, desde os antigos helênicos técnicas do seu aproveitamento vêm evoluindo aos sobressaltos, sempre demonstrando um ápice de desenvolvimento em períodos de escassez ou insuficiência em energia por fontes não renováveis ou em extinção. Inúmeros são os exemplos ao longo da história. Xenofonte, em seu Memorabilia (Livro III, cap. VIII, 431 - 355 a.C.) atribui à Sócrates a "receita" de uma casa solar capaz de explorar a luz e o calor do sol, aquecendo no inverno e protegendo no verão. Vitruvius ${ }^{1}$ (Ca. $100 \mathrm{aC}$ ) ressalta a importância do conhecimento das trajetórias do sol para a concepção e orientação dos edifícios assim como para a implantação de novas cidades. $O$ aproveitamento desta forma de energia na construção graças ao conhecimento de sistemas que hoje são classificados como "passivos" é, portanto, bastante conhecido por ter se perpetuado nas construções vernaculares e evoluído acompanhando o progresso da tecnologia. Tornou-se possível, hoje, construir aproveitando a energia solar com requintes de qualidade, salubridade,

\footnotetext{
1 VITRUVIUS, Marcus P. - The ten Books on Architecture. Translated by Morris H. Morgan. Dover Publications, re-edição (original de 1914), New York. ISBN: 486-20645-9.

A orientação em relação ao sol é mencionada com ênfase em dois livros, ou capítulos, da obra de Vitruvius. No Livro I (cap. IV, p.17), aparecem as diretrizes gerais para a escolha do sítio de uma cidade e como as trajetórias do sol devem ser levadas em conta. No Livro IV (cap. V, p.116), discorre sobre a orientação dos templos. No livro VI (cap. I, p.170) define as diretrizes para o projeto de edificações com mais detalhes, trazendo conselhos para os mais diversos tipos de cômodos. Há inclusive a descrição detalhada da casa grega. O livro IX (cap. VII, p.270-272). trata de astronomia em geral e geometria solar, demonstrando alto grau de conhecimento técnico.
} 
conforto ambiental, eficiência energética e ainda produzir a energia necessária para o desempenho das atividades cotidianas contemporâneas. Os recentes estudos sobre o efeito fotovoltaico e os assombrosos avanços na produção de células, módulos e painéis fotovoltaicos, cada vez mais eficientes, permitem repensar o uso da energia solar como fonte para a produção de energia elétrica, assim como abrem portas para que arquitetos, urbanistas e projetistas reformulem seus projetos de maneira a captar a maior quantidade de radiação possível. Sim, porque a priori, toda construção na superfície da Terra é solar. Esta declaração bombástica não é exagero, mas uma simples constatação, pois, de fato, as edificações recebem radiação direta, indireta, refletida ou difusa em sua envoltória durante o período diurno, com intensidade variável de acordo com a latitude e com as condições meteorológicas locais. A quantidade de radiação recebida pela edificação depende principalmente das orientações e inclinações dos planos que formam a envoltória da edificação.

Portanto, uma pergunta fundamental emerge desta consideração, a saber se a adoção desta forma de energia trará modificações na forma dos edifícios e no desenho urbano, vindo a transformar a paisagem das cidades?

Para responder a estas questões que envolvem a adoção da energia solar como fonte de energia e o aproveitamento da energia solar na arquitetura, ou pela arquitetura, o assunto deve ser abordado num contexto mais amplo, tentando identificar e englobar um grande número de aspectos que a envolvem. Ao lado das questões técnicas e construtivas que remetem a exeqüibilidade de uma edificação, arquitetos e urbanistas devem lidar com outras realidades, outras circunstâncias que estabelecem um rol de aspectos, variáveis e parâmetros em contextos diferentes, porém inter-relacionados.

\section{ASPECTOS GEOGRÁFICOS E POTENCIAL SOLAR}

O primeiro aspecto, talvez o mais imediato é aquele que expõe o potencial energético solar disponível num determinado local e diz respeito à posição geográfica e às características físicas do entorno. A latitude do local define o ângulo de inclinação da eclíptica solar em relação ao plano horizontal e os ângulos dos raios solares em relação á vertical do lugar em cada momento do dia e do ano. Junto com as condições macro e micro climáticas locais, como a nebulosidade, o número de horas de insolação direta, o estado e composição da atmosfera, determina-se o potencial de energia solar disponível. Nota-se que as condições climáticas são afetadas pela 
altitude, pela proximidade de vastas extensões de água, florestas ou de áreas urbanas densamente construídas. É uma constatação - e também uma verificação por meio de medições - que as regiões mais ensolaradas do planeta, desertos próximos à linha do equador, apresentam o maior potencial para captação da energia solar. Obviamente, toda esta energia não pode ser utilizada diretamente: seria preciso cobrir toda a superfície do país com painéis fotovoltaicos e, mesmo assim, a eficiência destes captadores está longe dos $100 \%$. A observação, no entanto, é pertinente e dá margem à reflexão. As formas de energia utilizadas hoje apresentam todas altos índices de eficiência, excelente rendimento e, sobretudo, são centralizadas, permitindo controle quase absoluto da produção e da distribuição. $E$ conferem altos lucros... A energia solar não pode, sozinha e por ora, substituir as fontes de energia que cobrem as necessidades da humanidade, garante os níveis de produtividade e precisam alimentar um sistema baseado no crescimento ad aeternum, hoje. Mas, combustíveis fósseis não são renováveis, são esgotáveis e poluem o ambiente. $\mathrm{A}$ energia hidrelétrica também traz impactos negativos no entorno com a instalação de grandes usinas e reservatórios. Usinas nucleares também demonstram alto rendimento e eficiência para produção de energia, no entanto, A implantação de novas usinas nucleares, após os recentes acidentes (Three Miles Island, Chernobyl e Fukushima) ficou comprometida a curto e médio prazo, até que a tecnologia visando a segurança de uso seja totalmente dominada.

Em escala nacional, as ações para a inclusão da energia solar na matriz energética, que derivam da avaliação do potencial de energia solar local, baseado em considerações geográficas, têm implicações nas esferas políticas, econômicas e culturais.

Numa escala menor, ou seja, de referência ao local das edificações, o micro clima influenciado pela topografia e pela existência de obstáculos naturais ou construídos, pela proximidade de vegetação de grande porte, que possam sombrear em determinados horários do dia, ajudam a refinar as estimativas do potencial solar no lugar específico estudado. Nestes casos, ações dependem das decisões no âmbito do projeto de arquitetura. Os conhecimentos dos contextos regionais e locais são essenciais no início de qualquer projeto de arquitetura, pois irão auxiliar o estabelecimento das diretrizes gerais e fornecer algumas respostas preliminares sobre o aproveitamento da energia solar e de que maneira, passiva ou ativa. A decisão afirmativa permite estabelecer estratégias quanto à implantação de uma edificação no terreno, a orientação das fachadas e o dimensionamento das aberturas, a necessidade de proteções ou sombreamentos, a produção de energia elétrica a partir do sol 
e, finalmente, o impacto, no caso o sombreamento, que a edificação irá projetar no entorno. Ao longo da história da arquitetura, confirma-se a solidez do conhecimento da geometria solar e de sua importância para o planejamento das construções.

\section{ASPECTOS TECNOLÓGICOS: SISTEMAS ATIVOS E PASSIVOS}

Embora não tenha se desenvolvido de maneira linear e constante, ao longo do tempo, mas ressurgido em intervalos de tempo irregulares, dependendo geralmente dos momentos de penúria energética, as técnicas de construção visando o aproveitamento da radiação solar têm demonstrado saltos qualitativos significantes quanto ao desempenho das soluções, notadamente durante o último século. As performances técnicas são bem mais visíveis no campo das engenharias, onde as ferramentas modernas têm se mostrado úteis no desenvolvimento de soluções objetivando eficiências máximas. Os exemplos das casas piloto construídas e monitoradas nos centros de pesquisa, como do MIT (Massachussets Institute of Technology) nos EUA ou na UFSC (Universidade Federal de Santa Catarina, Brasil), atestam esta atitude de busca pelo rigor técnico. No campo da arquitetura, que não pode ser confundido com construção, a abordagem é bastante diversa, porque a arquitetura não lida apenas com os aspectos técnicos, mas utiliza a técnica para determinados fins e busca harmonizá-los com aspectos formais e plásticos intrínsecos.

Os avanços nas pesquisas sobre o efeito fotovoltaico têm acenado com possibilidades novas para a produção de energia e provocado arquitetos e construtores quanto à sua incorporação na arquitetura. Um problema técnico, evidentemente, mas, sobretudo epistemológico.

Durante a segunda metade do século $\mathrm{XX}$, multiplicaram-se as pesquisas, trabalhos publicados, debates e congressos sobre a questão, em parte devido às pressões exercidas pelos problemas energéticos planetários, em parte movidos pelas inquietudes e angústias de arquitetos comprometidos com os caminhos futuros da arquitetura (CALDANA, 2005)2.

\footnotetext{
${ }^{2}$ CALDANA JR, Valter Luis - Projeto de arquitetura: caminhos. Tese de doutoramento apresentada na Faculdade de Arquitetura e Urbanismo da Universidade de São Paulo. Documento digitalizado em Pdf, São Paulo, 2005.
} 
Energia e eficiência energética das construções, com o objetivo de prover saúde e conforto nas edificações, tem sido o cerne das preocupações dos profissionais engajados com a sustentabilidade e tem envolvido principalmente arquitetos herdeiros da linha de pensamento orgânica.

Acelerados avanços tecnológicos na indústria ligada à construção e novidades em materiais com as mais diversas características e em componentes para a construção tem aquecido os mercados e proporcionado novas possibilidades para projetos. Paralelamente, ferramentas computadorizadas sofisticadas permitem simulações, cálculos e estimativas rápidas, eficazes e confiáveis para avaliar previamente o desempenho de soluções (ou soluções possíveis), trabalhando com um número cada vez maior de variáveis.

A tecnologia não constitui, portanto, um entrave à adoção de sistemas de energia solar na arquitetura. Há uma discussão mais delicada no âmbito da arquitetura em si onde se nota, com razão, uma inquietude inerente sobre os destinos e o papel da arquitetura vindoura ${ }^{3}$.

Há uma diferença importante a ser notada entre as técnicas desenvolvidas para os equipamentos solares com o objetivo primordial de alcançar o rendimento ou a eficiência máxima e a sua aplicação em projetos de arquitetura, lembrando que estes últimos não se destinam a máquinas, mas à espaços destinados ao exercício das mais diversas atividades que, portanto, buscam satisfazer outras funções que a mecânica, térmica, de iluminação ou energética e que dizem respeito às necessidades sociais, culturais e psicológicas humanas.

\section{PARADIGMAS DA ARQUITETURA}

No mundo contemporâneo (e isso não será privilégio do mundo ocidental) observamse os equívocos provocados pelo uso impensado e sem critério de tecnologias da construção ou a seu serviço. Tomemos o exemplo do ar condicionado, cujo uso se

\footnotetext{
${ }^{3}$ Cf. MONEO, Rafael - Inquietud teórica y estratégia proyectual en la obra de ocho arquitectos contemporáneos. Actar, EU, 2004. ISBN: 84-39551-68-1.
} 
espalhou a uma velocidade crescente nas últimas décadas do século $\mathrm{XX}$. Inicialmente louvado por Le Corbusier, em seu livro "Quand les cathédrales étaient blanches" (1937) após sua visita a Nova lorque, em 1928, porque este invento prometia liberar arquitetos e projetistas das limitações até então impostas pelas condições climáticas locais. De fato, as regiões de climas extremos obrigavam a adotar soluções construtivas que, por si só, mitigassem os efeitos negativos das condições ambientais extremas. Mas, os progressos da tecnologia paralela à arquitetura permitiram o desabrochar de um molde internacional, que pode ser encontrado em profusão em todos os rincões do planeta e que são totalmente independentes dos contextos ambientais locais. Torres de vidro, autênticos coletores solares, absorvem e armazenam quantidades, as vezes absurdas de calor, e demandam o aporte de grandes quantidades de energia elétrica, para retirar este calor excessivo. Em regiões de clima tropical estas soluções se mostram incoerentes e, em muitos casos, absurdas. É certo que a tecnologia dos equipamentos de ar condicionado conheceu uma evolução ímpar nestas últimas décadas e demonstram a capacidade em desenvolver equipamentos eficientes e econômicos em termos de consumo de energia. O mesmo é verdade para indústria ligada à iluminação artificial, assim com àquela dos materiais e componentes da construção civil. As recentes certificações e selos "verdes" aceleram a busca de soluções técnicas que busquem a eficiência energética das edificações, principalmente as comerciais, consumidoras vorazes de energia.

Timidamente, no final do século XIX, experimentos com energia solar acabaram sobrepujados pela existência e exploração de energias altamente eficientes - e rentáveis provenientes de fontes de alto rendimento, baratas e abundantes que se acreditavam mais do que suficientes para as necessidades da época. Este pensar, alimentado por um espírito de otimismo herdado do positivismo, fez acreditar no domínio total da natureza e no controle absoluto do homem sobre o seu meio, originando uma situação para a arquitetura do século $X X$ que se tornaria um problema no final do período quando as energias convencionais começaram a ser questionadas quanto à sua sustentabilidade. De qualquer maneira, enquanto as energias foram baratas e abundantes, os arquitetos souberam tirar partido destas fontes poderosas. A eletricidade foi incorporada com sucesso na produção e no uso dos espaços edificados transformando-os em micro climas absolutamente controláveis, independentes do clima externo e da hora do dia, pois a iluminação, doravante podia ser constante. O "Estilo Internacional" tornava-se uma realidade global e podia se construir qualquer coisa em qualquer lugar desde que houvesse energia elétrica que pudesse acionar os condicionadores de ar (aquecimento e/ou refrigeração) e restabelecer o conforto. 
Do mesmo modo que a eletricidade causou um impacto perceptível nos projetos e na arquitetura do século XX, é presumível acreditar que o aproveitamento da energia solar, quando prioritário nos programas de arquitetura, irá afetar não só o produto final, mas principalmente as posturas e, portanto, os processos de projeto.

A própria incorporação de técnicas solares passivas ostenta diferenças formais e, sobretudo, revela as atitudes dos arquitetos implícitas nas decisões adotadas durante o projeto.

Um olhar sobre a arquitetura do século XX evidencia a presença do sol em todos os projetos e particularmente nas obras de Le Corbusier onde a sua relação com este astro é expressa em todos os seus projetos, sejam eles de edifícios ou urbanos, ao longo sua carreira e explicitada quando declara, durante o Congresso Internacional de Arquitetura Moderna - CIAM -, em Atenas, que "os materiais do urbanismo são o sol, as árvores, o céu, o aço, o concreto, nesta ordem hierárquica e indissoluvelmente" (LE CORBUSIER, 1933) ${ }^{4}$.

Uma atitude de Le Corbusier, no projeto da Unidade de Habitação de Marselha surpreende: a de orientar o eixo principal do edifício no sentido Norte-Sul, expondo, assim, as fachadas maiores para o leste e para o oeste. Contradiz, ou pelo menos, subverte o senso comum, os princípios da casa grega de orientar a maior fachada para o equador (sul no hemisfério norte) de modo a beneficiar-se do calor do sol durante os meses mais frios do ano. A configuração dos apartamentos e sua disposição no edifício, no entanto, permitem maior insolação durante o dia todo. O calor é controlado graças a aposição de varandas ${ }^{5}$. Tal decisão confirma a hipótese de que posturas conscientes em relação ao aproveitamento do sol transformam a configuração final de um edifício e, mais importante, revisam os conceitos até então estabelecidos.

Do outro lado do Atlântico, os projetos das casas solares de George Fred Keck coincidem exatamente com períodos de dificuldades energéticas: depressão dos anos 1930 e guerra mundial. O maior mérito dos projetos de Keck é o de acomodar princípios solares antigos as técnicas construtivas de seu tempo e adaptá-las à linguagem da arquitetura moderna. Profundo conhecedor dos princípios construtivos gregos e

\footnotetext{
${ }^{4}$ LE CORBUSIER - La Carte d'Athènes - Paris : Points, 1957 . s/ ISBN .P. 82

${ }^{5}$ Cf, FRETIN, Dominique - De Helii Architecturis - Capítulo III - Le Corbusier e o sol.
} 
romanos, que ele mesmo cita, e dos movimentos aparentes do sol, Keck consegue demonstrar a compatibilidade entre o uso de técnicas passivas para aproveitamento da energia solar e a aparência moderna de suas casas. Poderia se dizer que suas estufas características são para a arquitetura moderna das regiões frias o que o quebrasol representa para a arquitetura moderna tropical.

A arquitetura de Frank Lloyd Wright tem um caráter distinto no sentido que o sol, com sua luz e calor, por assim dizer, são elementos integrantes da sua arquitetura, obedecendo à definição mesmo da arquitetura orgânica "na qual as formas devem ter o rigor necessário de um organismo natural e apresentar a mesma unidade" (HATJE, 1964). Dois exemplos marcantes, analisados no capítulo III, são: a casa da Cascata (1936) e a segunda casa Jacob (1944) e, cujas plantas, em última análise, são uma transposição fiel de um gráfico das trajetórias aparentes do sol para suas latitudes. Configurações, formas e implantações obedecem rigorosamente à geometria solar, enquanto materiais e elementos construtivos buscam graças a suas características térmicas (judiciosamente escolhidas) o melhor aproveitamento da energia solar. São exemplos primorosos do que hoje é classificado como arquitetura bioclimática. A prioridade dada ao sol é evidente nos dois casos e influencia e justifica toda a composição formal.

No Brasil, o exemplo de Rino Levi revela uma postura afirmada do arquiteto no que diz respeito aos seus projetos e à sua obra em relação ao sol. A questão energética emerge nem tanto como fruto de preocupações em economia de energia ${ }^{7}$, mas em decorrência de um racionalismo extremo na sua forma de projetar, com elegância e uso correto dos materiais. Rino Levi se serve das soluções da arquitetura para providenciar conforto interno da maneira mais natural possível. Esta atitude se nota na implantação do edifício do Banco Sul Americano, na Avenida Paulista, que não obedece a uma lógica esperada de mercado: o fato de virar o prédio para a Rua Frei Caneca, (rua secundária), pode ser explicada por uma questão de ângulos (uma reminiscências do antigo código Sabóia que determinava a altura máxima de um edifício em

\footnotetext{
${ }^{6}$ HATJE, Gerd (org.) - Dictionaire de l'architecture moderne. Fernand Hazan, Dijon 1964. Pp, 220-221.

${ }^{7}$ A cidade de São Paulo, onde se encontra a maioria da produção de Rino Levi, enfrentou (e ainda enfrenta) crises cíclicas de energia, em parte porque os investimentos em energia elétrica, sempre estiveram aquém do crescimento industrial e urbano acelerado e, portanto de uma demanda insaciável. $O$ fornecimento de energia elétrica da cidade depende dos reservatórios das cercanias e, portanto, das chuvas,situação periclitante nas épocas de secas prolongadas.
} 
função da largura da rua), ou por uma razão acústica para evitar o ruído da avenida Paulista (carros e bondes) ou ainda, por uma lógica associada à geometria solar: o prédio virado para a rua Frei Caneca teria uma orientação mais adequada para proteções (mais eficientes e mais econômicas), evitando o sobreaquecimento dos ambientes e das estruturas.

A escolha do alumínio para os quebrassóis pode ser questionada: muito caro para a época e o alumínio consome muita energia para sua produção. Foram usados por motivos de durabilidade e facilidade de manutenção, mesmo porque, na época, estas questões não eram prioritárias, e não havia escassez de energia.

\section{O EXEMPLO DE FREIBURG}

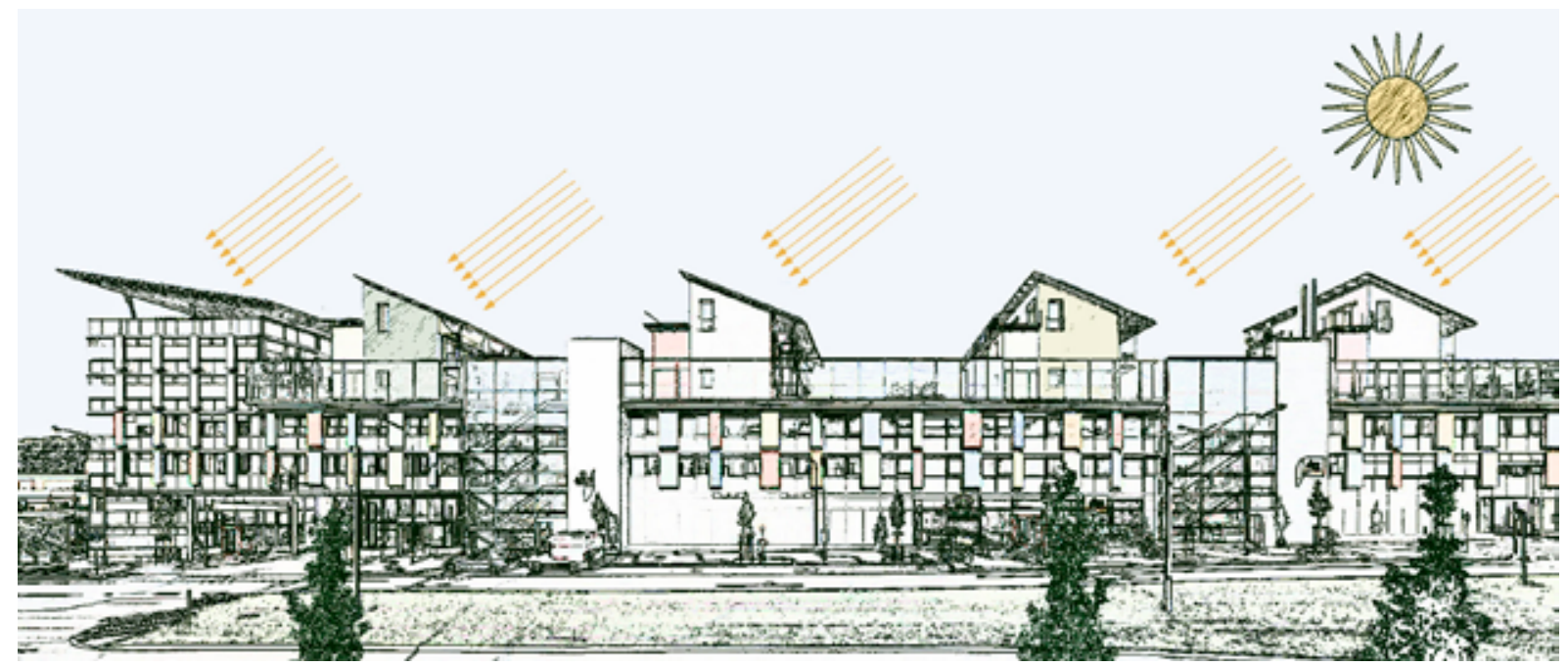

Figura 1 - SOLARSIEDLUNG, Freiburg, Alemanha - Arquiteto Rolf Dish

Eficiência energética, conforto e atransformação da energia solar incidente em eletricidade para abastecimento das unidades habitacionais e comerciais são evidenciados neste projeto: a distância entre os edifícios e a sua implantação, a inclinação dos telhados constituídos de painéis fotovoltaicos, a orientação dsa fachadas, a dimensão das aberturas e a escolha dos materiais em cada face, obedecem rigorosamente a critérios geométricos baseados nas trajetórias aparentes do sol e a condicionantes térmicas.

Croqui do autor - Fonte: http://greenlineblog.com/solarsiedlung-by-rolf-disch/

Na Alemanha, desde as últimas décadas do século $X X$, os projetos do arquiteto Rolf Dish, eminentemente solares, revelam transformações que ultrapassam os limites da arquitetura. Incentivados e apoiados por legislações que contemplam a energia solar na matriz energética nacional, apresentam soluções explicitamente concebidas para o 
aproveitamento total desta energia, por meio de soluções passivas e ativas, completamente integradas (e não disfarçadas) no desenho dos edifícios. Nos prédios do Solasiedlung (Bairro solar), por exemplo, os painéis fotovoltaicos são a cobertura das unidades habitacionais e não sobrepostos sobre um telhado convencional (Figura 1). O desenho dos edifícios acompanha os princípios fundamentais de uma arquitetura bioclimática com soluções solares passivas, criando edifícios sui generis. Mas, além do desenho de cada unidade, há um desenho urbano que rege a disposição dos edifícios, derivado da decisão de aproveitamento máximo da energia solar, obediente à geometria das trajetórias do sol para a latitude local. A exposição ao sol é garantida a todas as unidades, tanto para o correto funcionamento das soluções arquitetônicas passivas, como para a produção de eletricidade pelos painéis fotovoltaicos. A realização deste projeto evidencia também a importância do apoio de legislação específica sobre o uso da energia solar como resultado de uma vontade político-econômica clara neste aspecto.

\section{MASDAR CITY E RAS AL-KHAIMAH}

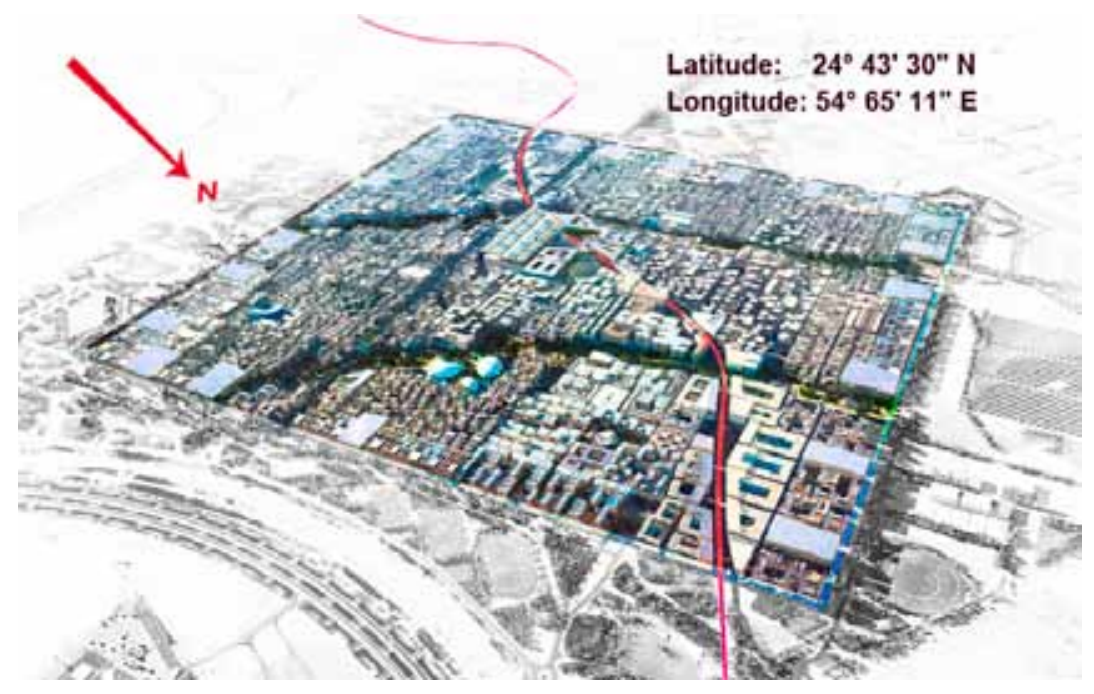

Figura 2 - Masdar City projeto de Foster\&Partners. Uma cidade compacta lembrando assentamentos urbanos mais antigos de regiões desérticas.

Desenho do autor. Fonte: http:// www.fosterandpartners.com/ projects/masdar-development/

Os projetos audaciosos de Masdar City (Figura 2) e do conjunto de edifícios sede da companhia Masdar (Masdar Headquarter - figura 3), no emirado de Abu-Dabi, neste início de milênio, são, por outro lado, um resultado de apostas para um futuro que se quer sustentável, ao menos em termos de uso e conservação da energia. Masdar City quer ser um centro de pesquisas tecnológicas em energias alternativas. Assim, os projetos da cidade e do edifício sede (Masdar Headquarters) constituem exemplos formidáveis e extraordinários por terem sido encomendados em regiões 
produtoras de petróleo, porém que revelam, com esta atitude, a conscientização de um próximo esgotamento de seus recursos energéticos e econômicos, preocupações com um porvir durável e estável a médio e longo prazo assim como tomadas de decisões assertivas sobre ações a serem empreendidas em curto prazo. A cidade foi concebida para ser compacta e não possui vias para veículos automotores individuais, mas apenas para pedestres ou bicicletas. Distâncias maiores serão alcançadas por sistemas de transporte coletivo. Parte da energia necessária será fornecida graças a captação de energia solar.

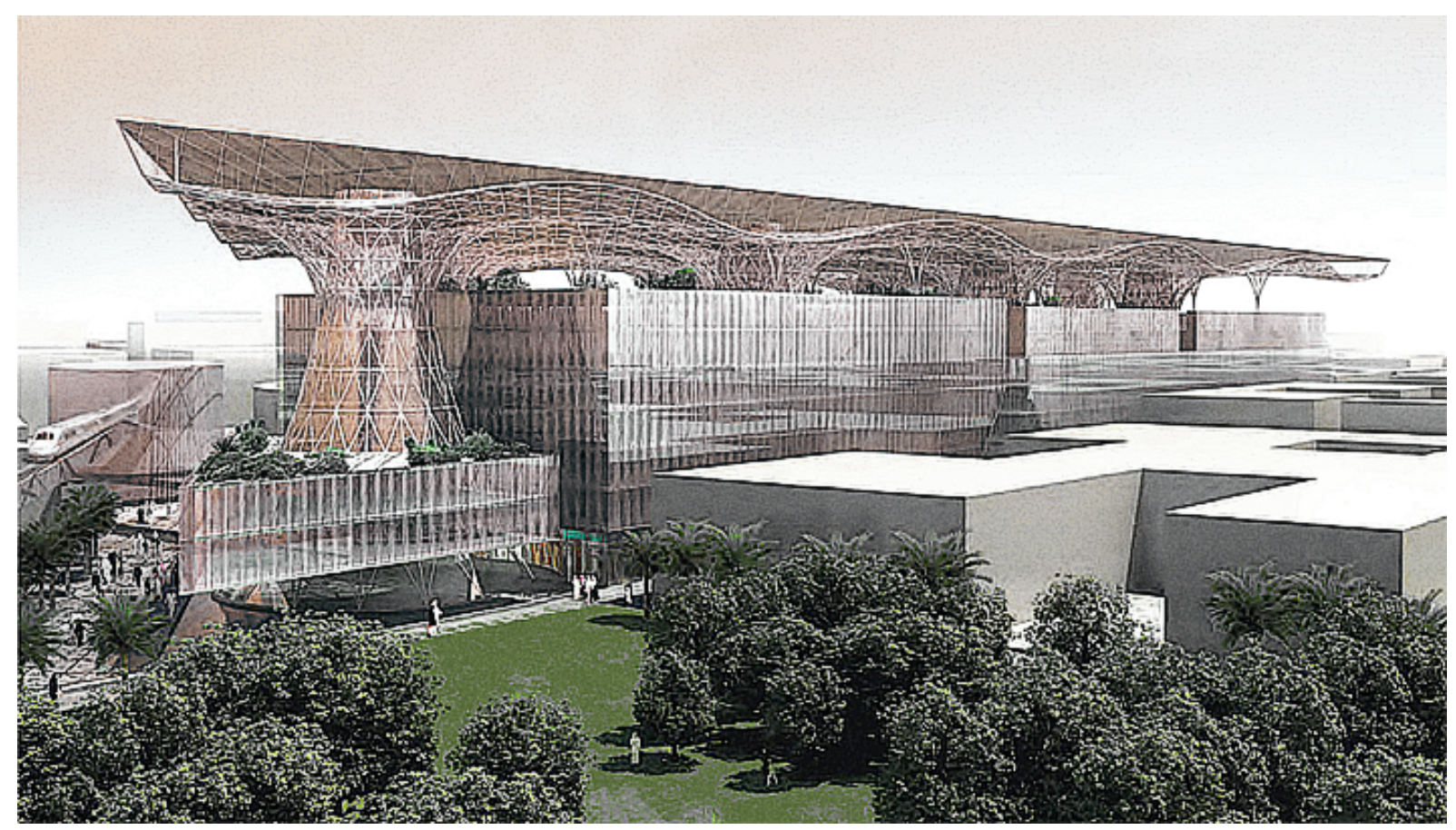

Figura 3 - Masdar Headquarters projeto de Adrian Smith + Gordon Gill Architecture.

Um conjunto de edifícios que produzirá mais energia do que irá consumir

Foto trabalhada pelo autor. Veja vídeo em: http://www.youtube.com/watch?v=TA_Hkv42B4o

Em relação à arquitetura dos edifícios sede da companhia Masdar (Masdar Headquarters - Figura 3) que esperam produzir mais energia do que irão consumir graças a exploração de diversas formas de energia, incluindo a solar, persiste a indagação se as propostas formais apresentam transformações, mudanças ou uma ruptura com os conceitos de um urbanismo e de uma arquitetura tradicionais. Em realidade, não. Muitos conceitos de uma arquitetura e de um desenho urbano vernacular de regiões desérticas podem ser reconhecidos nestes projetos contemporâneos. Basta uma olhada na cidade de Shibbam Hadramaut, no lêmen, datada do século XVI, Património Mundial da Humanidade pela UNESCO desde 1982 e que recebeu la alcunha de 
"Manhattan do deserto" (Figuras 4 e 5), para constatar as semelhanças formais das cidades e de seus edifícios, densamente agrupados, uns sombreando os outros.

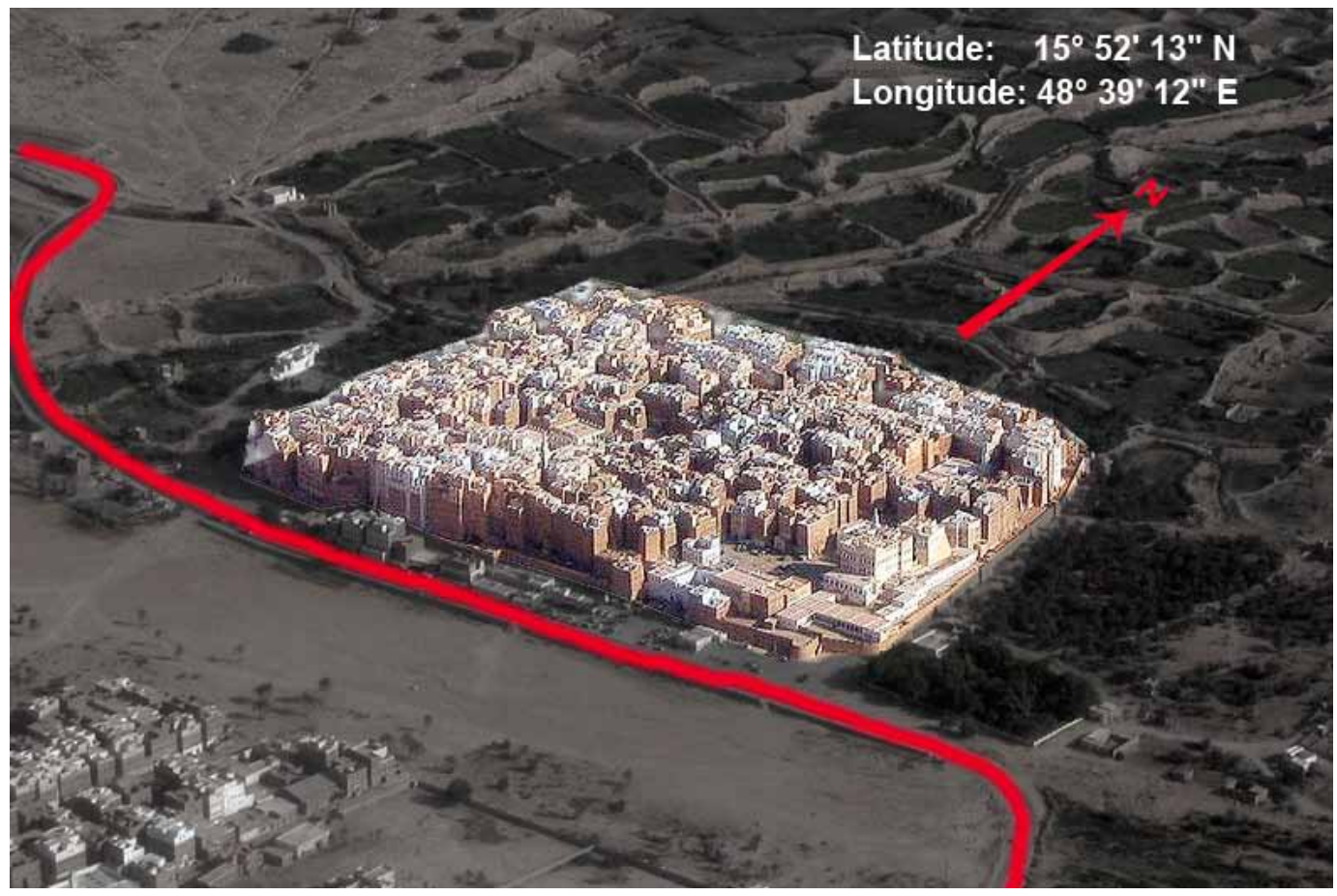

Figura 4 - Cidade de Shibam Hadhramaut, lemen.

Desenho do autor. Fonte: http://www.geolocation.ws/v/P/61589247/shibam-hadramaut-yemen-/en

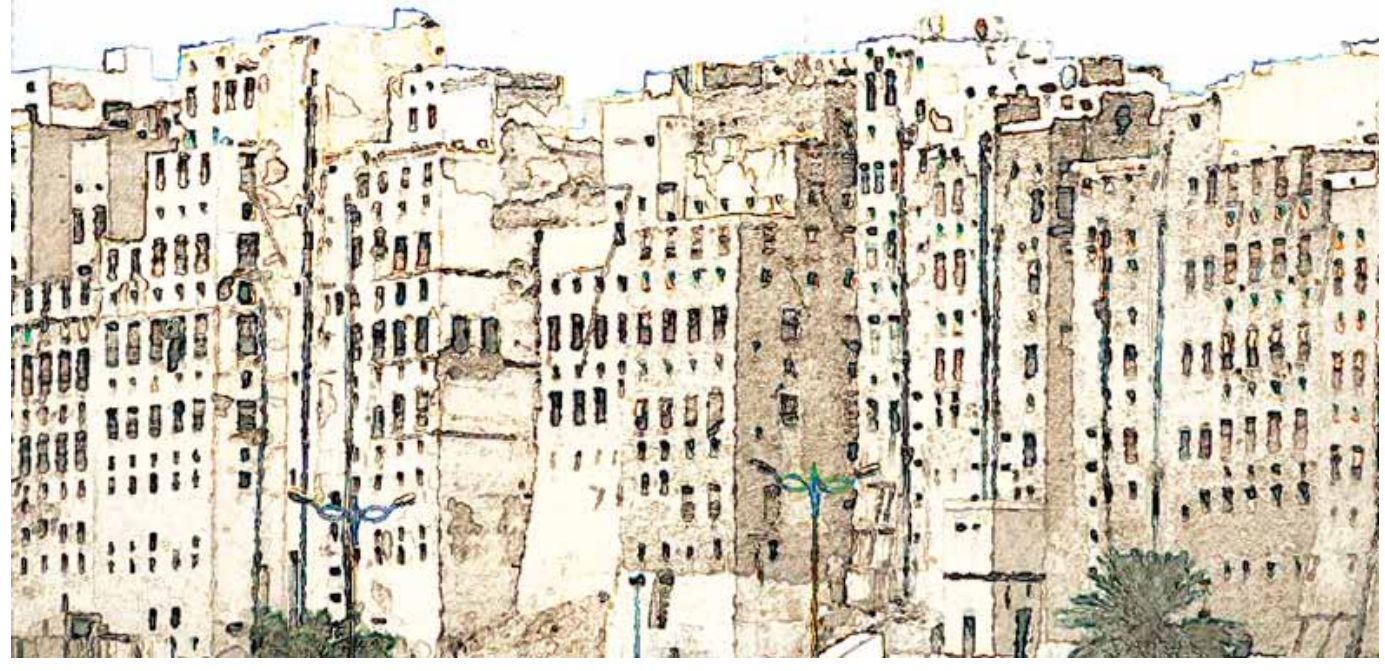

Figura 5 - Cidade de Shibam Hadhramaut, lemen. Alta densidade e edifícios agrupados para sombreamento durante o dia. Material de base pesado para amortecer a amplitude térmica. Desenho do autor. Fonte: http://www.boston.com/bigpicture/2008/10/stormbattered_yemen.html 
O próprio desenho de Masdar City (Figura 2) proposto pelo escritório Foster \& Partners, como da cidade ecológica de Ras Al-Khaimah (Figura 6), projetada por Rem Koolhaas, ambas nos Emirados Árabes Unidos (EAU), de planta quadrada, com edifícios aglutinados formando de longe uma massa compacta, para se proteger do sol e das tempestades de areia, se assemelha às cidades mais antigas implantadas em desertos.

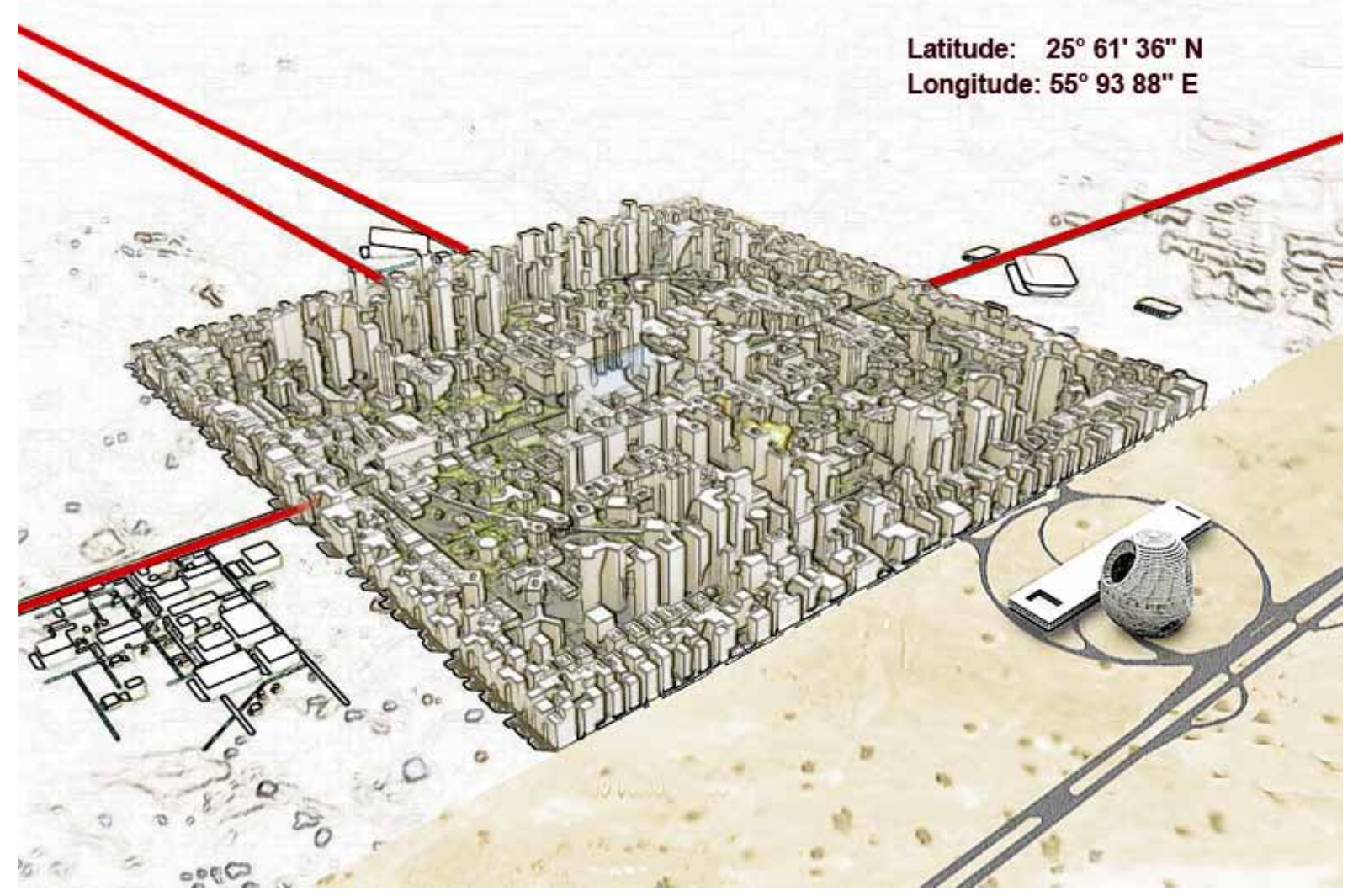

Figura 6 - Maquete da cidade de Ras Al-Khaimah, Rem Koolhaas, 2008.

Cidade compacta para proteção do calor e das tempestades de areia.

Desenho do autor. Fonte: http://www.greatbuildings.com/architects/Rem_Koolhaas.html. Acessado em 30/03/2009.

Nota-se uma diferença brutal, por exemplo,I com o desenho da cidade de Dubai, calcado em modelos à americana, com eixos de circulação monumentais (para carros) ladeados de edifícios isolados, também monumentais, esculturais, porém com suas fachadas envidraçadas totalmente expostas ao sol, portanto inabitáveis sem o uso de ar condicionado (o que implica no consumo enorme de energia para seu funcionamento).

Segundo Adam Smidt, um dos arquitetos responsáveis pelo projeto vencedor de concurso para a sede da companhia Masdar (Masdar Headquarters), "não é a forma que 
muda, mas os processos". O aspecto formal do conjunto de edifícios remete ao aspecto das cidades islâmicas, com os volumes bem marcados em prismas retos, e os espaços intermediários estreitos, sombreados e próprios para a circulação e/ou convívio de pedestre. A vasta cobertura do conjunto, com painéis fotovoltaicos assemelha-se a um grande pergolado que lembra as ruas cobertas dos "souks" árabes, criando um micro clima propício ao desenvolvimento de atividades em todo conforto.

Os projetos da cidade de Masdar, assim como do Masdar Headquarter abrem uma nova visão sobre o papel e o significado da forma na arquitetura. Principalmente sobre como o ambiente construído reage e interage com o clima, neste caso, em pleno deserto, com o sol. O aspecto plástico, formal dos edifícios e da cidade, mesmo se abordados sob um ponto de vista funcionalista, energético, ostenta uma aparência agradável. Seus espaços internos convidam ao usufruto. Ao identificar o potencial formal de projetos ambientalmente sustentáveis, HAGAN (2001) argumenta que "o prazer estético se tornou tão necessário quanto ético na formação de uma sociedade que busca o bem estar do maior número de pessoas" ${ }^{8}$. Tal afirmação em reiterar a idéia de que o aproveitamento da energia solar na arquitetura não significa apenas a justaposição de equipamentos que provêm energia ou a substituem, mas que integrados ao processo de projeto trazem um significado novo aos espaços e, finalmente, à arquitetura.

\section{CONCLUSÃO: MITOS E VERDADES SOBRE A ENERGIA SOLAR}

O aproveitamento da energia solar na arquitetura tem sido alvo de polêmicas. À frente das controvérsias, há a questão do custo considerado elevado. De fato, mesmos os sistemas apoiados em técnicas passivas, para aproveitar o calor, a luz ou para proteger de uma insolação intensa numa edificação sempre representam um investimento inicial adicional. Resta verificar, a médio e longo prazo, qual o retorno financeiro em função dos benefícios alcançados que deveriam ser considerados em estimativas de custo/beneficio.

Quanto aos sistemas fotovoltaicos, seus altos custos eram justificados até pouco tempo atrás, pois os processos de produção do silício utilizado nas células fotovoltaicas

\footnotetext{
${ }^{8}$ HAGAN, Susanah. Taking Shape, a new contract between architecture and nature. Architectural Press, Oxford, 2001.
} 
só tornavam possível o seu uso em casos excepcionais como na indústria aeroespacial, para satélites, por exemplo, onde o abastecimento em energia solar é a única solução possível. $O$ rendimento das primeiras células fotovoltaicas de silício era baixo e seus altos custos relativos descartavam qualquer perspectiva de uso para outras finalidades na superfície terrestre, salvo com a justificativa da impossibilidade de abastecimento com outras formas de energia, em lugares afastados e sem infraestrutura energética. Já não é mais o caso. A evolução das pesquisas e da indústria demonstra o contrário com novos materiais, processos de produção e aperfeiçoamento da eficiência das células. As apostas e os investimentos nesta forma de energia na arquitetura realizados na última década comprovam este fato: os painéis fotovoltaicos instalados nas edificações da cidade de na Alemanha, a cobertura do Stade de Suisse em Berna, Suíça, a recente instalação de painéis fotovoltaicos sobre a cobertura do auditório Paulo VI ( projetado e construído pelo arquiteto Pier Luigi Nervi) ou ainda o projeto do Masdar Headquarter pelos arquitetos Adam Smidt e Gordon Gill. Estes poucos exemplos anunciam novas perspectivas de aproveitamento de energia solar e, principalmente, a inclusão de novos parâmetros para projetos futuros. O que antes era uma solução alternativa para locais afastados, agora está se generalizando e sendo incorporado na arquitetura.

Outro argumento desfavorável aponta a inconstância e a irregularidade da radiação solar sobre a superfície da terra, pois é cíclica (devido à rotação da terra - dia e noite) e está sujeita ás variações das condições do tempo. Uma sucessão de dias nublados, por exemplo, compromete a eficiência dos sistemas. Porém parte da energia não utilizada de imediato pode ser estocada sob forma de calor (água ou materiais de alta capacidade térmica) ou eletricidade em baterias. Há ainda a possibilidade de acoplar os sistemas solares em sistemas híbridos ${ }^{9}$ ou interligá-los à rede de energia elétrica local ${ }^{10}$.

Os defensores da energia solar argumentam que ela é infinita e inesgotável. Na verdade, apenas uma pequena parcela da energia emitida pelo sol atinge o planeta e, desta, uma quantidade menor chega à superfície da terra, dependendo ainda das condições meteorológicas locais. Quanto ser inesgotável, é verdade, para a escala de tempo da humanidade.

\footnotetext{
${ }^{9}$ Cf, FRETIN, Dominique - De Helii Architecturis. Tese de doutorado, Universidade Mackenzie, 2009. Capítulo I. ${ }^{10}$ Idem.
} 
É também apontada como uma energia "limpa", verde, o que é sensato em termos de energia. Porém, a produção de materiais e componentes para equipamentos solares depende de processos de extração e transformação de matérias primas, assim como de processos industriais que, estes, causam impactos negativos no meio ambiente. Extensas superfícies de coletores solares podem ocasionar o aquecimento local, causando efeito "ilha de calor". Basta imaginar uma cidade inteira captando energia solar por meio de coletores de aquecimento e painéis fotovoltaicos.

No entanto, o maior atrativo da energia solar é sua "gratuidade", um estímulo para os pesquisadores, um revigoramento para os consumidores e um pesadelo para as concessionárias de energia. A energia que vem do sol é gratuita, mas os equipamentos para captação, transformação e armazenamento, assim como sua manutenção, não o são. Isto sem mencionar os investimentos financeiros aplicados em pesquisas e produção. 


\section{REFERÊNCIAS BIBLIOGRÁFICAS}

AYRES NETTO, Gabriel - Código de obras "Arthur Saboya". Edições Lep, São Paulo, 1947. S/ ISBN.

CALDANA JR, Valter Luis - Projeto de arquitetura: caminhos. Tese de doutoramento apresentada na Faculdade de Arquitetura e Urbanismo da Universidade de São Paulo. Documento digitalizado em Pdf, São Paulo, 2005.

FRETIN, Dominique - De Helii Architecturis - Capítulo III - Le Corbusier e o sol. Tese de doutorado. Universidade Presbiteriana Mackenzie. Arquitetura e Urbanismo, São Paulo, 2009.

HAGAN, Susanah. Taking Shape, a new contract between architecture and nature. Architectural Press, Oxford, 2001.

HATJE, Gerd (org.) - Dictionaire de l'architecture moderne. Fernad Hazan, Dijon 1964.

LE CORBUSIER - La charte d'Athènes - Paris : Points, 1957. s/ ISBN

ONEO, Rafael - Inquietud teórica y estratégia proyectual en la obra de ocho arquitectos contemporáneos. Actar, EU, 2004. ISBN: 84-39551-68-1.

RODRIGUES \& MATAJS - Um banho de sol para o Brasil, o que os aquecedores solares podem fazer pelo meio ambiente e sociedade. São Lourenço da Serra: Vitae Civilis, 2004.

VITRUVIUS, Marcus P. - The ten Books on Architecture. Translated by Morris H. Morgan. Dover Publications, re-edição (original de 1914), New York. ISBN: 486-20645-9. 